\title{
CORRESPONDENCE
}

\section{Ease public concern over oil pipeline}

The need for environmental scientists to address the effects of tar-sands mining in Canada (Nature 468, 476; 2010) should be extended to the impacts of downstream operations.

Communities across the northern High Plains region of the United States are concerned about the risks of piping crude oil from Canadian tar sands across ecologically sensitive prairie and through an important recharge zone of the Ogallala Aquifer - the route of the proposed Keystone XL pipeline through the Nebraska Sand Hills.

The public debate is being conducted largely in the absence of scientific evidence about risks to water resources and aquatic ecosystems. This causes misinformation to circulate: for example, local stakeholders commonly believe that any oil released from a ruptured pipeline could contaminate the entire High Plains groundwater supply - based on the widespread misconception of an aquifer as an underground lake. Others, by contrast, believe that spilled oil would be harmlessly sequestered in the aquifer.

Much of the blame for these misconceptions must be down to poor communication with the public by scientists. However, scientists themselves are often hampered from providing technical input because of their limited access to data - as has happened with the Keystone XL proposal. Important data pertaining to this have not been divulged to the public, such as the fluid chemical composition and the maximum pipeline leakage volumes.

Disclosure of relevant data must be comprehensive if the risks associated with the pipeline are to be properly assessed. John B. Gates University of Nebraska-Lincoln, USA. jgates2@unl.edu

\section{Sustainable cities: seeing past the trees}

The problems facing our cities call for a holistic approach, not just for ecological solutions (Nature 468, 173; 2010). We also need to consider the resilience of the changes we make to the urban landscape in the name of sustainability (see www. urban-futures.org) and strike a balance between the benefits and disadvantages of these strategies.

Take street trees planted to improve biodiversity. They reduce air pollution by increasing particle deposition and replenishing oxygen, yet may also exacerbate it by reducing ventilation. They provide shade but limit passive solar heating. Their amenity value may be undermined by high costs for repairing infrastructure damaged by ground shrinking and swelling. Although they help to mitigate light pollution, trees are likely to increase lighting requirements, and although they store water they may need irrigating - and so on.

A continuing positive outcome will depend on thoughtful assessment of the competing and shifting aspects of sustainability.

Rob MacKenzie, Tom Pugh

Lancaster University, UK. r.mackenzie@lancs.ac.uk Chris Rogers University of Birmingham, UK.

\section{Time to underpin Wikipedia wisdom}

Wikipedia, the world's largest online encyclopaedia, is regarded with suspicion by some in the scientific community - perhaps because the wiki model is inconsistent with traditional academic scholarship (Nature $468,359-360 ; 2010)$. But the time has come for scientists to engage more actively with Wikipedia.

Type any scientific term into any search engine and it is likely that a Wikipedia article will be the first hit. Ten years ago, it would have been inconceivable that a free collaborative website, written and maintained by volunteers, would dominate the global provision of knowledge. But Wikipedia is now the first port of call for people seeking information on subjects that include scientific topics. Like it or not, other scientists and the public are using it to get an overview of your specialist area.

Wikipedia's user-friendly global reach offers an unprecedented opportunity for public engagement with science. Scientists who receive public or charitable funding should therefore seize the opportunity to make sure that Wikipedia articles are understandable, scientifically accurate, well sourced and up-to-date.

Many in the scientific community will admit to using Wikipedia occasionally, yet few have contributed content. For society's sake, scientists must overcome their reluctance to embrace this resource.

Alex Bateman, Darren W. Logan Wellcome Trust Sanger Institute, Hinxton, UK. agb@sanger.ac.uk

\section{Guest authors: for contributors only}

In your Careers feature on tenured academic positions (Nature 468, 123-125; 2010), you recommend that those seeking tenure should "Name a senior department member as a co-author on your papers if you're in Europe". But this regretfully common practice should be weeded out, not encouraged.

Such a recommendation would be worthwhile if it were to motivate a genuine collaboration and result in a significant contribution from the senior scientist to the paper.

Mark J. van Raaij Centro Nacional de Biotecnologia, Spain. mjvanraaij@cnb.csic.es

\section{Guest authors: no place in any journal}

In the pursuit of tenure, you encourage academics in Europe to include a senior department member as co-author on their papers (Nature 468, 123-125; 2010). Regardless of any geographical limitation, it was very disappointing to see this endorsement of guest authorship published in Nature.

Richard M. Glass Journal of the American Medical Association, Chicago, Illinois, USA.

richard.glass@jama-archives.org

Editor's note Nature requests author contributions statements and does not condone guest authorship (see go.nature.com/ uzgbki). The intended meaning of the ambiguous sentence was that tenure-track scientists should seek out senior department members as collaborators and contributing co-authors.

CONTRIBUTIONS

Items for Correspondence may be sent to correspondence@nature. com after consulting the author guidelines at http://go.nature.com/ cmchno. They should be no longer than 350 words. Readers are also welcome to comment online on anything published in Nature: www.nature.com/ nature. 